\title{
The role of urbanisation on international migrations. A case study of EU and ENP countries
}

\author{
Vicente Royuela \\ AQR Research Group-IREA \\ Universitat de Barcelona \\ Avda. Diagonal, 690. \\ 08034 Barcelona (Spain) \\ email: vroyuela@ub.edu \\ Telf +34.93 .403 .57 .32$ \\ Fax +34.93 .402 .18 .21$
}

\begin{abstract}
This article estimates the impact of the urbanisation rates as pull factor of international migration between the European Union and the countries involved in the European Neighbouring Policy. The 1970-2000 period was investigated by using a gravitational model and estimates were obtained by using a a wide fixed-effects structure. The main finding was that changes in urbanisation matter more as a pull factor than changes in GDP per capita. This may be linked to the existence of greater opportunities arising in growing cities and to the fact that in the period of analysis these opportunities had been more important in small and medium sized cities than in large cities. In addition, it appears that immigrants not only look for monetary outcomes by migrating, but also cue on non-economic territorial features.
\end{abstract}




\section{INTRODUCTION}

Between 2004 and 2007, 12 countries joined the European Union (EU). Former EU neighbours became EU members and consequently a range of new, poorer and politically less stable and less democratic countries bordered the EU. In preparation for this, the European Commission produced a communication in 2003 titled: The Wider Europe Neighbourhood, A New Framework for Relations with our Eastern and Southern Neighbours (COM 104 final, 2003), where a unified EU policy towards its neighbouring countries was proposed. As remarked in Wesselink and Boschma (2012), the goal of this new unified policy is to create a ring of friendly, stable and prosperous countries around the European Union in order to guarantee stability along the outer borders of the EU. -While the former neighbouring policy ended in EU accession, the new policy does not offer an accession perspective to countries. However, it does promote close political cooperation, close economic integration and ultimately, access to the unified market. Access to this large market is a positive stimulus promoting, on one hand, political and institutional changes towards democratic governance and market liberalisation and, on the other, adoption of EU moral values and norms (Monastiriotis and Borrell, 2012). The European Commission decided at the time that the European Neighbourhood Policy (ENP) would build on existing policies, allowing for convergence between existing policies until the end of the multiannual framework in 2006. In the following multiannual framework (2007-2013), the ENP has incorporated all previous policies as well as new instruments to guarantee a coherent institutional structure supporting the ENP (Com 393 final, 2003). The ENP is not only seen as an organism concerned with policies and several authors (Diez, 2005; Hyde-Price, 2006; Gawrich et al, 2010) consider ENP as a tool to essentially project its own interests to outside its periphery by containment of negative spillovers and externalities (illegal migration or security concerns). ${ }^{1}$

The 2006 evaluation of the ENP reaffirmed that the ENP's influence was stronger on trade and economic reforms than on the progress of democratic and human rights reforms. Based on this evaluation, the Commission drew a list of recommendations, and in particular

\footnotetext{
${ }^{1}$ The countries under the European Neighbouring Policy are: Algeria, Armenia, Azerbaijan, Belarus, Egypt, Georgia, Israel, Jordan, Lebanon, Libya, Moldova, Morocco, Palestine, Syria, Tunisia and Ukraine. Because of data constraints I have excluded Palestine of the analysis and due to its special interest, I have included Russia. More information on the ENP can be accessed at http://eeas.europa.eu/enp/
} 
concluded that free movement of people should be a more central focus of the ENP (COM 774, 2007). In fact, among the main bilateral agreements between EU and ENP countries one can cite migration issues, such as readmission agreements and visa facilitation agreements (for instance for Armenia, Georgia, Moldova and Ukraine), or illegal migration agreements (Morocco and Tunisia).

Indeed, most of the osmosis between the EU and the ENP countries is taking place through population flows. As recognised in the Europe 2020 strategy, the EU has a clear demographic challenge for the next decades and will have to import foreign labour force, according to dire demographic forecasts. This in the context of ageing populations, low birth-rates, and prospects of the collapse of social security systems. Moreover, the response to global competition and competitiveness depend on the ability to retain and attract skilled workers.

Today, about 200 million people, i.e. around three per cent of the world's population, live outside their country of birth. Contrary to what happened during the industrial period of the 19th century, the majority of migrants today end up in developed countries, immigrants represent more than $12 \%$ of the total population in OECD countries (Gheasi et al. 2012). Increases in migration flows from developing to developed countries have occurred in parallel to growth of between-country inequalities, which exceeded $80 \%$ of the total global inequality in the 1950s (Milanovic, 2011). From a micro perspective (Borjas, 1987), migrants estimate the costs and benefits of moving to alternative international locations and migrate to where the expected discounted net returns are greatest over some time horizon. From a macro perspective, migrant's decisions are clearly related to the process of economic development, as assumed by a large literature (Lewis, 1954; Ranis and Fei, 1961; Harris and Todaro, 1976; Todaro, 1976), which is a transformation that is usually linked to urbanisation. Many of these models assume that the expected income of a potential immigrant depends on the probability of finding a job, which is more likely to happen in expanding cities. After all, labour mobility is the human side of the agglomeration story.

Among all the potential pull factors attracting migration flows (income differences, employment rates, inequality, etc.), an aspect that has not been widely considered in the academic literature is the role of cities, separate from their economic role. On the assumption that urbanisation promotes economic growth, it is also associated with more 
opportunities, as man-made amenities are more efficiently provided in cities. As Williamson puts it, "urban amenities associated with government services may well serve as a partial offset to the higher cost-of-living in the cities" (Williamson 1988, p 435). Several works (as Kundu, 2009 or Kim and Cohen, 2010) have analysed the association between international immigration and urbanisation. However, as stressed in the 2009 World Development Report, "an important insights of the agglomeration literature - that human capital earns higher returns where it is plentiful - has been ignored by the literature of labour migration" (World Bank, 2009, p. 158).

In this article I analyse the migration from ENP countries to the EU over the 1970-2000 period, with a particular emphasis on the role of urbanisation as pull factor. Following is a brief review of the stylised facts of migration and urbanisation. Section 3 presents the theoretical background and section 4 presents the empirical model and the estimation results. Finally, section 5 concludes with the main findings.

\section{EMPIRICAL BACKGROUND}

In this section I explore the main world trends in migration and in urban urbanization found in the literature, with special emphasis on EU and ENP countries. For this analysis, data were of 197 countries for the period 1960-2000 and were obtained from the World Bank Bilateral Migration Database. ${ }^{2}$ This database provides information on international bilateral migrant stocks, mostly based on census and population register records. Özden et al. (2011) describe the 1960-2000 database and highlight the main global migration trends. For 2010, I used the 2010 World Bank Bilateral Migration Matrix. ${ }^{3}$ The variables on population and urbanisation belong to the World Bank World Development Indicators. ${ }^{4}$ Table 1 shows the main demographics trends in the EU and ENP countries and other world regions. Population growth has slowed down over the last 40 years, although several world regions still had annual growth rates in excess of $2 \%$ in 2010, mainly in Africa and Western Asia.

\footnotetext{
2 Access at http://data.worldbank.org/data-catalog/global-bilateral-migration-database. I used the version collected and revised by Ramos (2013).

${ }^{3}$ http://go.worldbank.org/JITC7NYTT0. The 2010 data are used here to describe the major trends, but will not be considered for the estimates. This is because the census data from the 2000 round of censuses were supplemented with the latest available data from national-level sources and, consequently, the available data may not accurately reflect recent trends (Migration and Remittances Factbook 2011).

${ }^{4} \mathrm{http}$ ///data.worldbank.org/data-catalog/world-development-indicators. Urban population refers to people living in urban areas as defined by national statistical offices. As recognised by the WDI, countries differ in the way they classify population as "urban" or "rural".
} 
Interestingly, these areas of rapid growth have not shown particularly high rates of emigration. Immigration has been particularly important in the more developed areas, such as Europe, Northern America, and Oceania.

ENP-East countries and Russia display a demographic decline over the last two decades. In fact, Eastern Europe is the only subregion in the World with negative rates of population growth. On the contrary, ENP-South countries show high population growth rates, which have caused the population in these countries to triple from 1960 (65 million inhabitants) to 2010 (203 million). The emigration rates have been particularly large in the ENP-East countries (15\% consistently during the period), while the immigration rates, albeit large, are lower and have been decreasing. The ENP-South countries have had higher emigration than immigration rates. Russia has reversed the sign of these rates, and since 2000 the immigration rate has been larger than the emigration rate.

Ramos (2013) has deeply analysed the destination of migrations from ENP countries and has found a high heterogeneity. For instance, while some countries, for example Israel during the whole period or Russia during the last thirty years, have been net receivers of migration, other countries (e.g. Belarus, Egypt or Tunisia) have exported population. An additional interesting feature is that migration is highly concentrated in some destination countries: most migrants from Algeria or Tunisia go to France, while most migrants from ENP-East countries go to Russia. Geographical proximity or strong political, economic or colonialist linkages play a role in this regard. Actually, the EU has not always been the main destination of migrants from ENP countries, for example Egyptians choose Saudi Arabia as first destination and Lebanese prefer to migrate to the United States. Migration between ENP countries has been substantial in the more recent period, particularly between ENPEast countries since the collapse of the Soviet Union.

Table 2 presents the basic picture of the world's urbanisation trends. Urban world population has increased from $33 \%$ in 1960 to $51 \%$ in 2010 (16 percentage points). Urban concentration has also risen in the last 50 years (6 percentage points), being more important in America, Oceania, and in several other subregions, such as Southern Africa and Western Asia. However, the global urbanisation trend may have different causes in large and in median and small cities (i.e. below one million inhabitants). In the latter, urban population has risen from $20 \%$ of the total world population in 1960 to $32 \%$ in 


\begin{tabular}{|l|ccccc|}
\multicolumn{4}{c|}{} & \multicolumn{5}{c|}{ Population growth } & annual rates \\
\cline { 2 - 7 } \multicolumn{1}{c|}{} & $\mathbf{1 9 6 0}$ & $\mathbf{1 9 7 0}-$ & $\mathbf{1 9 8 0}-$ & $\mathbf{1 9 9 0 -}$ & $\mathbf{2 0 0 0 -}$ \\
\hline Africa & $2.5 \%$ & $2.7 \%$ & $2.8 \%$ & $2.5 \%$ & $2.3 \%$ \\
Northern & $2.4 \%$ & $2.3 \%$ & $2.5 \%$ & $2.3 \%$ & $1.3 \%$ \\
Central, Eastern, Southern, Western & $2.5 \%$ & $2.7 \%$ & $2.8 \%$ & $2.5 \%$ & $2.4 \%$ \\
America & $2.0 \%$ & $1.8 \%$ & $1.6 \%$ & $1.5 \%$ & $1.1 \%$ \\
Northern & $1.3 \%$ & $1.1 \%$ & $1.0 \%$ & $1.2 \%$ & $0.9 \%$ \\
Central, South \& Caribbean & $2.7 \%$ & $2.4 \%$ & $2.0 \%$ & $1.6 \%$ & $1.2 \%$ \\
Asia & $2.2 \%$ & $2.1 \%$ & $1.9 \%$ & $1.5 \%$ & $1.2 \%$ \\
Central \& Western & $2.8 \%$ & $2.6 \%$ & $2.5 \%$ & $1.9 \%$ & $2.1 \%$ \\
East, South \& Southeast & $2.2 \%$ & $2.1 \%$ & $1.9 \%$ & $1.5 \%$ & $1.1 \%$ \\
Europe & $0.8 \%$ & $0.5 \%$ & $0.4 \%$ & $0.1 \%$ & $0.2 \%$ \\
EU15 & $0.8 \%$ & $0.4 \%$ & $0.3 \%$ & $0.3 \%$ & $0.5 \%$ \\
EU28 & $0.8 \%$ & $0.7 \%$ & $0.4 \%$ & $-0.2 \%$ & $-0.2 \%$ \\
Oceania & $2.0 \%$ & $1.7 \%$ & $1.6 \%$ & $1.4 \%$ & $1.6 \%$ \\
\hline
\end{tabular}

\begin{tabular}{|rrrrrr|}
\hline \multicolumn{7}{|c|}{ Emigrants as \% of local population } \\
\hline $\mathbf{1 9 6 0}$ & $\mathbf{1 9 7 0}$ & $\mathbf{1 9 8 0}$ & $\mathbf{1 9 9 0}$ & $\mathbf{2 0 0 0}$ & $\mathbf{2 0 1 0}$ \\
\hline $2.9 \%$ & $2.9 \%$ & $2.9 \%$ & $2.6 \%$ & $2.5 \%$ & $2.9 \%$ \\
$2.6 \%$ & $2.2 \%$ & $2.1 \%$ & $2.4 \%$ & $2.0 \%$ & $2.5 \%$ \\
$2.9 \%$ & $3.0 \%$ & $2.9 \%$ & $2.7 \%$ & $2.5 \%$ & $3.0 \%$ \\
$1.3 \%$ & $1.5 \%$ & $2.0 \%$ & $2.5 \%$ & $3.4 \%$ & $3.8 \%$ \\
$1.0 \%$ & $1.1 \%$ & $1.1 \%$ & $1.0 \%$ & $1.1 \%$ & $1.0 \%$ \\
$1.6 \%$ & $1.9 \%$ & $2.6 \%$ & $3.4 \%$ & $4.8 \%$ & $5.4 \%$ \\
$1.8 \%$ & $1.5 \%$ & $1.5 \%$ & $1.5 \%$ & $1.6 \%$ & $1.7 \%$ \\
$4.2 \%$ & $5.4 \%$ & $6.4 \%$ & $7.1 \%$ & $7.5 \%$ & $6.6 \%$ \\
$1.6 \%$ & $1.3 \%$ & $1.2 \%$ & $1.1 \%$ & $1.2 \%$ & $1.3 \%$ \\
$7.8 \%$ & $8.0 \%$ & $7.6 \%$ & $7.7 \%$ & $7.2 \%$ & $7.4 \%$ \\
$5.8 \%$ & $6.2 \%$ & $5.9 \%$ & $5.5 \%$ & $5.0 \%$ & $5.3 \%$ \\
$11.0 \%$ & $10.1 \%$ & $8.6 \%$ & $8.8 \%$ & $10.1 \%$ & $9.5 \%$ \\
$1.8 \%$ & $2.0 \%$ & $2.7 \%$ & $3.3 \%$ & $4.3 \%$ & $4.1 \%$ \\
\hline
\end{tabular}

\begin{tabular}{|rrrrrr|}
\multicolumn{7}{|c|}{ Immigrants as \% of local population } \\
\hline $\mathbf{1 9 6 0}$ & $\mathbf{1 9 7 0}$ & $\mathbf{1 9 8 0}$ & $\mathbf{1 9 9 0}$ & $\mathbf{2 0 0 0}$ & $\mathbf{2 0 1 0}$ \\
\hline $2.9 \%$ & $2.3 \%$ & $2.0 \%$ & $1.6 \%$ & $1.5 \%$ & $1.5 \%$ \\
$4.9 \%$ & $4.2 \%$ & $3.4 \%$ & $3.5 \%$ & $2.4 \%$ & $3.5 \%$ \\
$2.7 \%$ & $2.1 \%$ & $1.9 \%$ & $1.4 \%$ & $1.4 \%$ & $1.4 \%$ \\
$4.7 \%$ & $4.0 \%$ & $4.2 \%$ & $4.6 \%$ & $5.5 \%$ & $5.8 \%$ \\
$6.8 \%$ & $6.6 \%$ & $7.9 \%$ & $9.8 \%$ & $12.7 \%$ & $13.7 \%$ \\
$2.8 \%$ & $2.0 \%$ & $1.6 \%$ & $1.3 \%$ & $1.2 \%$ & $1.1 \%$ \\
$1.9 \%$ & $1.6 \%$ & $1.3 \%$ & $1.3 \%$ & $1.1 \%$ & $1.1 \%$ \\
$7.9 \%$ & $8.7 \%$ & $8.8 \%$ & $9.9 \%$ & $8.6 \%$ & $9.0 \%$ \\
$1.5 \%$ & $1.2 \%$ & $0.9 \%$ & $0.7 \%$ & $0.6 \%$ & $0.5 \%$ \\
$4.9 \%$ & $5.8 \%$ & $6.3 \%$ & $7.2 \%$ & $7.7 \%$ & $9.2 \%$ \\
$3.9 \%$ & $5.3 \%$ & $6.2 \%$ & $6.9 \%$ & $8.2 \%$ & $10.9 \%$ \\
$4.8 \%$ & $4.3 \%$ & $3.6 \%$ & $3.9 \%$ & $3.2 \%$ & $3.1 \%$ \\
$13.3 \%$ & $15.3 \%$ & $15.0 \%$ & $15.5 \%$ & $15.5 \%$ & $17.9 \%$ \\
\hline
\end{tabular}

\begin{tabular}{|l|rrrrr|}
\hline ENP - South & $2.7 \%$ & $2.6 \%$ & $2.6 \%$ & $1.9 \%$ & $1.7 \%$ \\
ENP - East & $1.2 \%$ & $0.8 \%$ & $0.6 \%$ & $-0.4 \%$ & $-0.4 \%$ \\
Russia & $0.8 \%$ & $0.6 \%$ & $0.6 \%$ & $-0.1 \%$ & $-0.3 \%$ \\
\hline
\end{tabular}

$$
\begin{array}{|rrrrrr|}
\hline 3.5 \% & 4.6 \% & 5.2 \% & 5.4 \% & 4.7 \% & 5.2 \% \\
15.1 \% & 14.8 \% & 14.1 \% & 15.6 \% & 15.1 \% & 15.0 \% \\
7.0 \% & 8.1 \% & 8.4 \% & 8.9 \% & 7.1 \% & 7.1 \% \\
\hline \multicolumn{1}{|c|}{} & & & & \\
\hline 3.0 \% & 2.8 \% & 2.6 \% & 2.6 \% & 2.6 \% & 2.8 \% \\
\hline
\end{array}
$$$$
\text { Total }
$$$$
\begin{array}{lllll|}
2.0 \% & 1.9 \% & 1.8 \% & 1.4 \% & 1.2 \% \\
\hline
\end{array}
$$

Note: EU 28 includes only the 13 countries that joined the EU since 2004 . 
Table 2. World Urbanization trends

\begin{tabular}{|c|cccccc|}
\cline { 2 - 7 } \multicolumn{1}{c|}{} & \multicolumn{6}{c|}{ Urban Population } \\
\cline { 2 - 7 } \multicolumn{1}{c|}{} & $\mathbf{1 9 6 0}$ & $\mathbf{1 9 7 0}$ & $\mathbf{1 9 8 0}$ & $\mathbf{1 9 9 0}$ & $\mathbf{2 0 0 0}$ & $\mathbf{2 0 1 0}$ \\
\hline Africa & $18 \%$ & $23 \%$ & $28 \%$ & $32 \%$ & $36 \%$ & $40 \%$ \\
Northern & $42 \%$ & $44 \%$ & $45 \%$ & $49 \%$ & $54 \%$ & $59 \%$ \\
Central, Eastern, Southern, Western & $17 \%$ & $22 \%$ & $27 \%$ & $31 \%$ & $35 \%$ & $39 \%$ \\
America & $59 \%$ & $64 \%$ & $69 \%$ & $72 \%$ & $77 \%$ & $80 \%$ \\
Northern & $70 \%$ & $74 \%$ & $74 \%$ & $75 \%$ & $79 \%$ & $82 \%$ \\
Central, South \& Caribbean & $49 \%$ & $57 \%$ & $65 \%$ & $71 \%$ & $75 \%$ & $79 \%$ \\
Asia & $20 \%$ & $23 \%$ & $26 \%$ & $32 \%$ & $37 \%$ & $43 \%$ \\
Central \& Western & $37 \%$ & $44 \%$ & $50 \%$ & $57 \%$ & $58 \%$ & $61 \%$ \\
East, South \& Southeast & $19 \%$ & $21 \%$ & $25 \%$ & $30 \%$ & $36 \%$ & $41 \%$ \\
Europe & $57 \%$ & $63 \%$ & $68 \%$ & $71 \%$ & $72 \%$ & $73 \%$ \\
EU15 & $65 \%$ & $70 \%$ & $73 \%$ & $74 \%$ & $75 \%$ & $77 \%$ \\
EU28 & $45 \%$ & $51 \%$ & $58 \%$ & $62 \%$ & $62 \%$ & $63 \%$ \\
Oceania & $67 \%$ & $71 \%$ & $71 \%$ & $71 \%$ & $70 \%$ & $71 \%$ \\
\hline
\end{tabular}

\begin{tabular}{|rrrrrr|}
\hline \multicolumn{7}{|c|}{ People living in cities of more than 1 } \\
million \\
\hline $\mathbf{1 9 6 0}$ & $\mathbf{1 9 7 0}$ & $\mathbf{1 9 8 0}$ & $\mathbf{1 9 9 0}$ & $\mathbf{2 0 0 0}$ & $\mathbf{2 0 1 0}$ \\
\hline $7 \%$ & $9 \%$ & $10 \%$ & $11 \%$ & $12 \%$ & $13 \%$ \\
$21 \%$ & $23 \%$ & $23 \%$ & $24 \%$ & $26 \%$ & $29 \%$ \\
$6 \%$ & $8 \%$ & $9 \%$ & $10 \%$ & $11 \%$ & $12 \%$ \\
$29 \%$ & $33 \%$ & $34 \%$ & $35 \%$ & $37 \%$ & $38 \%$ \\
$38 \%$ & $41 \%$ & $40 \%$ & $41 \%$ & $43 \%$ & $45 \%$ \\
$22 \%$ & $26 \%$ & $30 \%$ & $31 \%$ & $33 \%$ & $35 \%$ \\
$9 \%$ & $10 \%$ & $12 \%$ & $13 \%$ & $15 \%$ & $17 \%$ \\
$13 \%$ & $17 \%$ & $20 \%$ & $21 \%$ & $23 \%$ & $23 \%$ \\
$9 \%$ & $10 \%$ & $11 \%$ & $12 \%$ & $14 \%$ & $16 \%$ \\
$14 \%$ & $15 \%$ & $15 \%$ & $16 \%$ & $16 \%$ & $16 \%$ \\
$18 \%$ & $19 \%$ & $19 \%$ & $19 \%$ & $19 \%$ & $19 \%$ \\
$6 \%$ & $7 \%$ & $7 \%$ & $7 \%$ & $7 \%$ & $7 \%$ \\
$38 \%$ & $41 \%$ & $43 \%$ & $42 \%$ & $41 \%$ & $40 \%$ \\
\hline \multicolumn{7}{|c|}{} & & & & \\
\hline
\end{tabular}

People living in medium and small cities

\begin{tabular}{rrrrrr|}
1960 & 1970 & 1980 & 1990 & 2000 & 2010 \\
\hline & $15 \%$ & $18 \%$ & $21 \%$ & $24 \%$ & $28 \%$
\end{tabular} \begin{tabular}{lllllll}
$12 \%$ & $15 \%$ & $18 \%$ & $21 \%$ & $24 \%$ & $28 \%$ \\
\hline
\end{tabular} $\begin{array}{llllll}21 \% & 21 \% & 21 \% & 24 \% & 28 \% & 30 \%\end{array}$ $\begin{array}{llllll}11 \% & 14 \% & 17 \% & 21 \% & 24 \% & 28 \%\end{array}$ $\begin{array}{llllll}29 \% & 32 \% & 34 \% & 37 \% & 40 \% & 42 \%\end{array}$ $\begin{array}{llllll}32 \% & 33 \% & 34 \% & 34 \% & 36 \% & 38 \%\end{array}$ $\begin{array}{llllll}32 \% & 33 \% & 34 \% & 34 \% & 36 \% & 38 \% \\ 27 \% & 31 \% & 35 \% & 39 \% & 42 \% & 44 \%\end{array}$ $\begin{array}{llllll}11 \% & 12 \% & 15 \% & 19 \% & 22 \% & 26 \%\end{array}$ $\begin{array}{llllll}23 \% & 27 \% & 31 \% & 36 \% & 36 \% & 38 \%\end{array}$ $\begin{array}{llllll}10 \% & 11 \% & 14 \% & 18 \% & 21 \% & 25 \%\end{array}$ $\begin{array}{llllll}43 \% & 48 \% & 53 \% & 55 \% & 56 \% & 57 \%\end{array}$ $\begin{array}{llllll}43 \% & 48 \% & 53 \% & 55 \% & 56 \% & 57 \% \\ 47 \% & 51 \% & 54 \% & 55 \% & 56 \% & 58 \%\end{array}$ $\begin{array}{llllll}47 \% & 51 \% & 54 \% & 55 \% & 56 \% & 58 \% \\ 39 \% & 44 \% & 51 \% & 54 \% & 55 \% & 55 \%\end{array}$ \begin{tabular}{lllllll} 
Oceania & $67 \%$ & $71 \%$ & $71 \%$ & $71 \%$ & $70 \%$ & $71 \%$ \\
\hline
\end{tabular}

$\begin{array}{llllll}29 \% & 30 \% & 29 \% & 29 \% & 29 \% & 31 \%\end{array}$

\begin{tabular}{|l|llllll|}
\hline ENP - South & $36 \%$ & $43 \%$ & $47 \%$ & $51 \%$ & $54 \%$ & $56 \%$ \\
ENP - East & $44 \%$ & $52 \%$ & $59 \%$ & $64 \%$ & $64 \%$ & $65 \%$ \\
Russia & $54 \%$ & $63 \%$ & $70 \%$ & $73 \%$ & $73 \%$ & $73 \%$ \\
\hline
\end{tabular}

\begin{tabular}{|llllll|}
\hline $16 \%$ & $19 \%$ & $20 \%$ & $20 \%$ & $20 \%$ & $20 \%$ \\
$10 \%$ & $12 \%$ & $14 \%$ & $15 \%$ & $15 \%$ & $16 \%$ \\
$14 \%$ & $15 \%$ & $16 \%$ & $17 \%$ & $17 \%$ & $18 \%$ \\
\hline
\end{tabular}

\begin{tabular}{|llllll|}
\hline $20 \%$ & $24 \%$ & $27 \%$ & $32 \%$ & $35 \%$ & $37 \%$ \\
$34 \%$ & $40 \%$ & $45 \%$ & $49 \%$ & $49 \%$ & $48 \%$ \\
$40 \%$ & $47 \%$ & $53 \%$ & $57 \%$ & $56 \%$ & $55 \%$ \\
\hline
\end{tabular}

Total \begin{tabular}{|llllll|}
\hline $33 \%$ & $36 \%$ & $39 \%$ & $43 \%$ & $47 \%$ & $51 \%$ \\
\hline
\end{tabular} 
2010, which is double the increase found in the larger cities. In fact, in Europe, small and median cities were responsible for more than $80 \%$ of the total urbanisation growth (more than $90 \%$ in the EU15). An increase in urbanisation rates occurred in all ENP countries, but the distribution between large and small and median cities was heterogeneous. Thus, in Armenia, Israel, Lebanon and Syria, more than one third of their total populations lives in large cities, while in Azerbaijan, Algeria and Jordan, for example, large cities have lost weight since 1960. As in other parts of the world, the increase in urban immigration rates was mainly driven by small and median cities (curiously, in Egypt, where Cairo has a huge importance, $90 \%$ of the increase in the urbanisation rate was due to the smaller cities).

\section{THEORETICAL BACKGROUND}

Migration exists as a response of geographic differences in the supply and demand for labour. The income maximisation framework (Roy, 1951) has been the basis for a large body of work on migration. Many efforts have been made to obtain a consistently applied analysis (Pedersen et al. 2008, Mayda 2010, Caragliu et al. 2012, Belot and Ederveen 2012). Many are consistent with a fully micro-founded model (Ortega and Peri 2009, Faggian and Royuela 2010, Grogger and Hanson 2011, Beine, et al. 2011, Bertoli and Fernández-Huertas Moraga 2011, Arzaghi and Rupashinga 2013).

Most of these efforts provide an empirical model in which the scale of migration, in terms of the stock of individuals from one country $i$ who choose to reside in country $j$ depends on the differences of the elements, such as wages, that enter into the utility function, once the specific costs (and benefits) of migration between $i$ and $j$ have been considered. Thus, a typical migration equation (Arzaghi and Rupashinga, 2013) would be:

$$
\ln m_{i j t}=\ln m_{i i t}+\left(\boldsymbol{X}_{i t}+\boldsymbol{X}_{j t}\right) \mathbf{B}+\boldsymbol{Z}_{i j} \boldsymbol{\Gamma}+\varepsilon_{i j t}
$$

Where $m_{i j t}$ represents migration from $i$ to $j$ at time $t, \boldsymbol{X}_{\boldsymbol{j} t}$ represents a vector of attributes of location $j$ at time $t, Z_{i j}$ is a vector that includes specific costs and benefits of migration from $i$ to $j, \varepsilon_{i j t}$ is an idiosyncratic disturbance, while $\mathbf{B}$ and $\boldsymbol{\Gamma}$ are two vectors of parameters. At this stage, the empirical approach faces two key issues: which factors are considered as determinants of migration and which should be the estimation procedure. 


\subsection{Factors affecting migration decisions}

The first step to operationalise the theoretical framework into a workable empirical model is to specify the 'common' part of the utility function. This implies both identifying push and pull factors together with specific migration benefits and costs. We face a typical problem in applied economics: to instrumentalise the generic economic concepts included in the predetermined component of the utility function.

Among all the papers analysed in the migration literature review, the utility that an individual expects to obtain thanks to migrating is usually based on the actual income differences (GDP per capita, income per capita, income per worker, activity rate, and unemployment rate), the demographic and education differences between countries, and even on social aspects such as inequality, poverty or civil rights and democratic variables. Many of them are pull factors, while others can be considered as a measurement of distance between countries. The information provided by simple physical distance between countries is supplemented bymeasures of "cultural distance" or even "financial distance". Other works have included a shorter list of variables. For instance, Ortega and Peri (2009) include income per capita, but also try to use the logarithm transformation of income, decomposition of income per worker and the employment rate, Also, controls are included, such as population size, inequality and several demographic variables.

Urbanisation, industrialisation and economic development tend to be parallel processes. Since Alfred Marshall (1890), there is a theoretical background justifying agglomeration economies. The sources of agglomeration economies are discussed by Duranton and Puga (2004), Rosenthal and Strange (2004) and Puga (2010). Different works have tried to measure the size of agglomeration economies or their sources, either by using a micro perspective (Glaeser and Maré, 2001, Combes et al. 2011) or a macro approach, which is the one followed here. In this vein, by adopting various measures of urbanisation, several studies report empirical results of a growth-enhancing effect of urbanisation on countries' income in the long run (Henderson 2003; Brülhart and Sbergami 2009). Additionally, the degree of urban concentration may be more important than urbanisation per se; the growth- 
enhancing effects of urbanisation, related to scale and agglomeration economies, and particularly in developing countries, are significant for large urban agglomerations but not for small ones.

Urbanisation may be the result of a push rather than a pull process. For example it may be due to violence and social conflict, natural catastrophes or a lack of opportunities. Bloom et al. (2008) compare industrialisation-driven urbanisation in Asia, which is considered as likely to enhance economic growth, with urbanisation due to population pressure and conflict in Africa, which is more than likely to be detrimental to growth. In Latin America, the absence of proper urban planning is also evident in certain countries (Angotti, 1996).

Thus, if urbanisation is expected to promote economic growth, it is likely to be associated with higher opportunities and larger migration flows. In this line, Kim and Cohen (2010) have analysed the influence of urbanisation rate on international migrations . Neumayer (2005) suggests that people living in cities in the origin country are likely to be better informed than rural inhabitants. Martin (2003) argues that migrants go to cities in developing countries to obtain a visa or to make arrangements for legal or illegal migration. In the destination country, large and growing urban areas indicate better job opportunities and higher salaries. The world-systems theory, one of Massey et al.'s (1993) theoretical frameworks on international migration, supports the idea that expanding global cities concentrate the educated and well-paid workforce that in turn demand unskilled workers, usually immigrating from abroad. This idea can be expanded from global cities (New York, London, etc.) to the gateway cities, i.e. in many countries there are a small number of traditional gateway cities, which are usually the largest metropolitan areas (Burghardt, 1971, Johnston, 1982, Frey, 1996, etc.). Consequently, large and increasing urban areas are expected to be associated with international migration. Nevertheless, size is not all: Frey (2002) has referred to a secondary migration process in which immigrants move from the gateway cities to the "domestic-migration-magnet" cities in the United States. Similarly, Sempere and Calatayud (2012) analysed remigration within Spain and reported that $25 \%$ of foreign immigrants reallocated within the country two years after their arrival.

This is consistent with recent OECD results, which stress that median and small agglomerations enjoy stronger levels of development. Several OECD reports (2009 a, b, and c) highlight the idea that growth opportunities are both significant in big urban areas 
and in smaller, more peripheral agglomerations. In this line, some authors have recently highlighted that economic growth does not need to depend exclusively on increasing urban concentration: "mega-urban regions are not the only possible growth pattern... context and institutions do matter when we consider economic geography” (Barca et al. 2012).

Finally, as stressed by Rodríguez-Pose and Ketterer (2012), “economic and noneconomic territorial features have been found to be essential elements determining utility differentials, and hence migration incentives of potential movers, across different territories" (p. 536). Amenities such as climate have been found in the literature to be important for migration(Florida, 2002; Partridge and Rickman, 2003, 2006, in the US and Chesire and Magrini, 2006 and Rodríguez-Pose and Ketterer, 2012, in Europe). A large amount of manmade amenities are efficiently provided in cities and consequently urbanisation does not only facilitate higher wages but also lead to more opportunities, which is in accord with Sen's concept of 'capabilities'. Thus, Sen (1987) claims that the selection of indicators should consider two issues: the actual outcome of peoples' decisions, and also their capabilities, i.e. the opportunities they have. In our view these capabilities are wider in cities than in rural areas.

\subsection{Estimation strategy}

The applied work in migration analysis has used a wide list of perspectives to account for the effects of the factors entering the migration equation. Several works (Kim and Cohen 2010 and Mayda 2010) consider separately the origin $\left(\boldsymbol{X}_{\boldsymbol{i t}}\right)$ and destination $\left(\boldsymbol{X}_{\boldsymbol{j} t}\right)$ characteristics in the regression. Others have included the difference between these characteristics, both linearly $\left(\boldsymbol{X}_{i t}-\boldsymbol{X}_{j t}\right)$ (Faggian and Royuela 2010) or by using a ratio $\left(\boldsymbol{X}_{\boldsymbol{j} t} / \boldsymbol{X}_{\boldsymbol{i t}}\right)$ (Clark et al. 2007). Finally, other works have focused on the specific cost or benefits between $i$ and $j\left(\boldsymbol{Z}_{\boldsymbol{i} \boldsymbol{j}}\right)$ (Caragliu et al. 2012 analysed cultural distance, while Belot and Ederveen 2012 studied the linguistic distance between countries).

Thus, several works have tried to capture explicitly pull and push factors along with specific cost or benefits of migrating. Nevertheless, these works do not consider what has been called 'Multilateral Resistance to migration'. In the words of Bertoli and Fernández-Huertas Moraga (2011, p. 9), "a term that captures the influence upon migration from country $i$ to 
country $j$ exerted by the opportunities to migrate to other destinations", Migration does not only depend on the attractiveness of the destination, but also on how this relates to the opportunities to move to other destinations. Given the difficulty to account for this effect directly, a usual approach (Ortega and Peri, 2009) has been to introduce dyadic origin-time dummies and monadic destination dummies in the set of regressors. This approach does not allow identifying the effects of any regressor which does not vary across destinations.

Cheng and Wall (2005) show that the treatment of heterogeneity using paired-fixed effects factors can alter gravity model estimates and that alternative fixed-effects models are special cases of a general model that may be inducing biased estimates for the parameters of the control variables. Ruiz and Villarubia (2007) generated a gravitational model that controlled for multilateral resistance by including both country-origin and countrydestination time dummies. This resulted in the inclusion in the model of $2 * \mathrm{~N} * \mathrm{~T}$ dummies. Finally, Cheng and Wall (2005) considered country-pair intercepts that included the effects of all omitted variables that were cross-section specific and constant over time (distance, contiguity, language, and culture). They finally included a global time trend, interpreted as an indicator of the extent of 'globalisation', as the common trend towards greater flow volumes independently of the size of the economies.

A robust picture of the influence of urbanisation on international migrationis drawing by following several approaches: First I considered the characteristics of the origin and destination of migrations by using traditional variables together with several distance measures. In subsequent stages I included alternative structures of fixed effects for effects that were specific to origin or origin-destination characteristics., These were supposed to capture omitted variables problems, at the cost of not being able to identify several effects.

This treatment of non-observed heterogeneity is parallel to that of variance heterogeneity of the disturbance term. Thus, the literature has suggested the use of non-linear models such as Poisson (Santos Silva and Tenreyro, 2006) or Negative Binomial and Zero-Inflated (Burger et al 2009) because heteroscedasticity can affect not only the efficiency of the estimator but also its consistency. Indeed, Arzaghi and Rupasingha (2013) follow Faggian and Royuela (2010) and compare the log linear against Poisson estimates. Following Guimaraes et al. (2003) using a fixed-effect Poisson regression is equivalent to using a conditional logit model in which individuals face a number of alternatives for migration. 
However, migration count data are usually overdispersed (data variance is larger than the mean), not fitting a Poisson model. Over-dispersion is usually associated to unobserved heterogeneity, typically occurring when observations are inter-correlated or have been collected from "clusters", or when the model has not been correctly specified (i.e. omitted variables, interactions, non-linear terms, incorrectly specified functional form, outliers, etc.). The negative binomial model allows for over-dispersion by including a measure of variance heterogeneity. In order to avoid the problem of incidental parameters I used the conditional ML estimator in the fixed-effects Poisson and Negative-Binomial models (see Cameron and Trivedi 2005 for a discussion on fixed-effects count models). When all fixed effects are considered, the estimation is conditioned to the dyadic origin-destination fixed effects (about four hundred), while the origin-time fixed effects (about sixty) are explicitly included in the regression. Whether this procedure really avoids the incidental parameters problem is an empirical issue, on the assumption that the issue can be broadly viewed as a problem of inference in the presence of many nuisance parameters (Arellano and Hahn, 2006).

In this line, I considered as starting point the log linear model, using $\ln \left(m_{i j t}+1\right)$ as the dependent variable to adjust for zero migration counts, and subsequently I used Poisson and Negative Binomial models for the count variable, $m_{i j t}$.

\section{DATA AND ESTIMATION RESULTS}

The dependent variable was the stock of migrants born in the 16 ENP countries and residing in the $28 \mathrm{EU}$ countries from 1970 to $2000 .{ }^{5}$ Grogger and Hanson (2011) use a theoretical model which considers the scale of migration in terms of the stock of individuals from one country that choose to reside in another. Ortega and Peri note that their theoreticallygrounded empirical specification can be interpreted as determining a relationship between stocks of migrants, or the analogous flows (Ortega and Peri, 2009). Admittedly, the use of stocks "creates a tension with the underlying micro-foundations of the gravity model" (Beine et al., 2014, p16). Nevertheless in our case, given the wide structure of fixed effects included in a subsequent stage, the changes in the stock of migrants were interpreted in terms of changes ('within' variation) and in economic terms can be interpreted as net flows.

\footnotetext{
${ }^{5}$ As mentioned in section 2, the 2010 migration database may not reflect accurately some recent trends.
} 
Table 3 displays the descriptive statistics of the variables considered in our model. The migration stock of people from ENP countries in EU countries was, on average some 15.000 people in 2000. This figure, which has been increasing does not display an excessive number of zeroes, as the first quartile is always away from that figure. Finally, in all thevariables considered, the between cross-country standard deviation was much larger than the within (time) standard deviation. This is a note of caution when interpreting results with a large amount of fixed effects because they will act as proxies for short-run rather than long-run effects.

Table 3. Descriptive statistics

\begin{tabular}{|c|c|c|c|c|c|c|c|c|}
\hline Migration $_{\mathrm{ij}}$ & Mean & S.D. & Min & $\mathbf{Q}_{1}$ & $\mathbf{Q}_{2}$ & $\mathbf{Q}_{3}$ & $\operatorname{Max}$ & \\
\hline 1960 & 10057.2 & 71355.6 & 0 & 1 & 25 & 419.5 & 1177694 & \\
\hline 1970 & 12486.7 & 92642.8 & 0 & 2 & 35.5 & 465.5 & 1493990 & \\
\hline 1980 & 13040.9 & 86786.8 & 0 & 3.5 & 77.5 & 791.5 & 1424707 & \\
\hline 1990 & 15839.6 & 93767.4 & 0 & 14 & 150 & 1914.5 & 1375771 & \\
\hline \multirow[t]{3}{*}{2000} & 14242.9 & 77209.3 & 0 & 51 & 418 & 2640.5 & 1057135 & \\
\hline & & \multicolumn{3}{|c|}{ Standard Deviation } & & & Corr & \\
\hline & Mean & Overall & Between & Within & Min & Max & $\begin{array}{c}\text { with } \\
\text { migration }\end{array}$ & $\begin{array}{l}\text { with log } \\
\text { GDP pc }\end{array}$ \\
\hline Migration $_{\mathrm{ij}}$ & 14491.3 & 86230 & 80419.8 & 31302.0 & 0 & 1493990 & & \\
\hline $\ln$ GDP pc ${ }_{j}$ & 9.181 & 0.846 & 0.773 & 0.351 & 6.957 & 10.867 & 0.054 & \\
\hline${\text { Urb. } \text { rate }_{j}}$ & 65.30 & 15.19 & 13.51 & 6.98 & 28.20 & 97.40 & 0.035 & 0.431 \\
\hline Urb. large cities $_{j}$ & 12.19 & 10.66 & 10.53 & 1.72 & 0 & 39.28 & 0.031 & 0.269 \\
\hline Urb. medium cities $_{j}$ & 53.11 & 17.37 & 16.09 & 6.58 & 6.42 & 94.70 & 0.007 & 0.152 \\
\hline
\end{tabular}

Among all the factors affecting migration decisions that were reviewed in section 3.1, I accounted for actual income (GDP per capita; ln GDP pc); demographic structure of the considered countries: the proportion of people aged 0-14 (pop_0_14) and the proportion of people older than 65 (pop_m65); and two proxies of the institutional framework: life expectancy at birth (life_exp) and installed telephones per capita (teleph_pc) in order to capture people's opportunities arising from man-made amenities not linked to urbanisation in every country. Other important variables, such as the unemployment rate or other institutional indices, were not considered because more than $50 \%$ of potential observations would be lost. I also included a list of distance metrics: distance between capitals, a dummy for contiguity, a dummy for common history (comcol=1 for common coloniser post 1945), and two linguistic distance dummies (comlang_ethno $=1$ if a language is spoken by at least 
$9 \%$ of the population in both countries and comlang_off $=1$ for a common official primary language).

At the first stage, Model 1 considered the following structure resulting from (1), including lagged origin $\left(\boldsymbol{X}_{\boldsymbol{i t - 1}}\right)$ and destination $\left(\boldsymbol{X}_{\boldsymbol{j} t-\mathbf{1}}\right)$ characteristics separately and also a set of distance $\left(\boldsymbol{Z}_{\boldsymbol{i j}}\right)$ metrics:

$$
\ln m_{i j t}=\alpha+\boldsymbol{X}_{\boldsymbol{j} t-\mathbf{1}} \mathbf{B j}+\boldsymbol{X}_{\boldsymbol{i t}-\mathbf{1}} \mathbf{B i}++\boldsymbol{Z}_{i \boldsymbol{j}} \boldsymbol{\Gamma}+\varepsilon_{i j t}
$$

Next, I included two different sets of dummies. Model 2 includes origin-time dummies (as in Ortega and Peri, 2009), accounting for any migration benefits or costs specific to the country of origin by year:

$$
\ln m_{i j t}=\alpha+\boldsymbol{X}_{\boldsymbol{j t - 1} \mathbf{B}} \mathbf{j}+\delta_{i t}+\boldsymbol{Z}_{\boldsymbol{i j}} \boldsymbol{\Gamma}+\varepsilon_{i j t}
$$

Thirdly (model 3), I included origin-destination dummies, accounting for any migration benefits or costs specific to the paired origin and destination countries (as in Bertoli and Hernández-Huertas Moraga, 2011):

$$
\ln m_{i j t}=\alpha+\boldsymbol{X}_{\boldsymbol{j} \mathbf{t - 1}} \mathbf{B j}+\boldsymbol{X}_{\boldsymbol{i t}-\mathbf{1}} \mathbf{B i}+\theta_{i j}+\varepsilon_{i j t}
$$

And finally (model 4), the model considered both sets of dummies:

$$
\ln m_{i j t}=\alpha+\boldsymbol{X}_{\boldsymbol{j} \boldsymbol{t}-\mathbf{1}} \mathbf{B j}+\delta_{i t}+\theta_{i j}+\varepsilon_{i j t}
$$

As described in the previous section, these specifications were estimated using a log linear model. The raw migration variable is count data, and therefore estimates we obtained by using Poisson and Negative Binomial models. All models were estimated using robust standard errors (using bootstrap for the Poisson and Negative Binomial specifications). 
Table 4 presents the results of the estimated log linear and negative binomial models. The models provided similar results. ${ }^{6}$ Model 1 accounted for migration pull and push factors through a list of variables. In addition, migration benefits or costs specific to origin and destination were proxied by using a list of distance metrics. In such specifications, almost all variables were significant and had the expected signs, i.e. thecountries with higher GDP received more immigrants and expulsed less emigrants. Nevertheless, urbanisation exhibited a negative and significant parameter for the destination countries and a positive parameter for the origin countries. Thus, more urbanised countries received less people and expulsed more people. This result is expected if we see urbanisation as an indicator of development. Then, GDP per capita and urbanisation would represent a sort of decreasing return of development.

Regarding the control variables, older countries received and expulsed more migrants., Proxies related with the country's institutional framework (i.e. life expectancy at birth and no. installed telephones per capita) were significant. All distance metrics were relevant, i.e. increasing physical distance decreased migration, while contiguity, having a common history, and language proximity favoured migration. Model 2 substituted the origin variables for origin country - time fixed effects. Outcomes were very similar to those of the former specification, which I interpret as proof of robustness of the results.

Model 3 substituted the origin-destination distance measurements for dyadic fixed effects, thus introducing fixed effects for the destination countries. Finally, model 4 included both sets of fixed effects. These two last specifications can be interpreted as short-run rather than long run results. ${ }^{7}$ In this line, models 1 and 2 demonstrate how people migrate towards richer and less urbanised countries. By contrast, models 3 and 4 report a non-significant parameter for GDP per capita, but a positive and significant parameter for urbanisation. Results were robust and were similar for the log linear and the negative binomial estimates.

\footnotetext{
${ }^{6}$ The Poisson estimates are presented at the appendix. The negative binomial performs better than the Poisson according to the likelihood statistics. In addition, the over-dispersion parameter is always significant. The Poisson estimates report different parameters for the urbanisation rates in comparison with the linear and the negative binomial. As we saw above, over-dispersion is usually associated to unobserved heterogeneity, what calls for the importance of dealing with it, as the consequence is more related with consistency than with efficiency (Santos Silva and Tenreyro, 2006). Therefore, I focus on the results of the lineal and negative binomial estimates.

${ }^{7}$ If we would assume a dynamic relationship, following Baltagi and Griffin (1984) and Pirotte (1999), the fixed effects estimates would capture the short run impact of the variable, being the pool estimation a mix of the long (which would be captured by the between estimate) and short estimates.
} 
Table 4. Estimates results. Urbanisation Rate

\begin{tabular}{|c|c|c|c|c|c|c|c|c|}
\hline & \multicolumn{4}{|c|}{ Log Lineal } & \multicolumn{4}{|c|}{ Negative Binomial } \\
\hline & Model 1 & Model 2 & Model 3 & Model 4 & Model 1 & Model 2 & Model 3 & Model 4 \\
\hline \multirow[t]{2}{*}{$\ln$ GDP pc dest } & $0.699 * * *$ & $0.518 * * *$ & -0.149 & -0.564 & 0.0143 & 0.102 & 0.193 & -0.0837 \\
\hline & 0.210 & 0.163 & 0.530 & 0.358 & 0.26 & 0.16 & 0.232 & 0.176 \\
\hline \multirow[t]{2}{*}{ Urbanisation rate dest } & $-0.0171 * *$ & $-0.0134 * *$ & $0.142 * * *$ & $0.101 * * *$ & $-0.0278 *$ & $-0.0282 * * *$ & $0.0312 * * *$ & $0.0279 * * *$ \\
\hline & 0.00858 & 0.00630 & 0.0477 & 0.0318 & 0.0149 & 0.00686 & 0.00877 & 0.007 \\
\hline \multirow[t]{2}{*}{ pop_0_14 dest } & -0.0101 & 0.00303 & $-0.149 * *$ & $-0.0874 * *$ & $-0.198 * * *$ & $-0.117 * * *$ & -0.0396 & -0.0357 \\
\hline & 0.0476 & 0.0378 & 0.0617 & 0.0354 & 0.0575 & 0.0327 & 0.0396 & 0.028 \\
\hline \multirow[t]{2}{*}{ pop_m65 dest } & $0.767 * * *$ & $0.821 * * *$ & -0.0819 & 0.0767 & $0.475 * * *$ & $0.803 * * *$ & 0.0506 & 0.053 \\
\hline & 0.0791 & 0.0573 & 0.113 & 0.0711 & 0.114 & 0.061 & 0.0742 & 0.056 \\
\hline \multirow[t]{2}{*}{ life_exp dest } & $0.409 * * *$ & $0.452 * * *$ & $-0.223 *$ & -0.0345 & $0.502 * * *$ & $0.577 * * *$ & $-0.135 * * *$ & $-0.0781 * *$ \\
\hline & 0.0586 & 0.0470 & 0.126 & 0.0830 & 0.0797 & 0.0484 & 0.0497 & 0.039 \\
\hline \multirow[t]{2}{*}{ teleph_pc dest } & $-0.0797 * * *$ & $-0.0924 * * *$ & $0.0477 * *$ & 0.00183 & $-0.0677 * * *$ & $-0.0999 * * *$ & $0.0223 *$ & $0.023 * * *$ \\
\hline & 0.0122 & 0.00954 & 0.0226 & 0.0144 & 0.0131 & 0.00815 & 0.0125 & 0.008 \\
\hline \multirow[t]{2}{*}{$\ln$ GDP $p c_{\text {origin }}$} & $-0.355^{*}$ & & 0.635 & & 0.216 & & 0.0585 & \\
\hline & 0.207 & & 0.640 & & 0.215 & & 0.225 & \\
\hline \multirow[t]{2}{*}{ Urbanisation rate origin } & $0.0432 * * *$ & & 0.0608 & & $0.0324 * *$ & & -0.00488 & \\
\hline & 0.0133 & & 0.0391 & & 0.0139 & & 0.0159 & \\
\hline \multirow[t]{2}{*}{ pop_0_14 origin } & 0.0338 & & 0.0726 & & $0.0435 *$ & & -0.00793 & \\
\hline & 0.0265 & & 0.0594 & & 0.0261 & & 0.0236 & \\
\hline \multirow{2}{*}{ pop_m65 origin } & $0.233 * * *$ & & -0.238 & & $0.337 * * *$ & & -0.152 & \\
\hline & 0.0882 & & 0.177 & & 0.0849 & & 0.0975 & \\
\hline \multirow{2}{*}{ life_exp origin } & $-0.134 * * *$ & & $-0.0996 *$ & & $-0.156 * * *$ & & -0.00257 & \\
\hline & 0.0253 & & 0.0529 & & 0.026 & & 0.0224 & \\
\hline \multirow[t]{2}{*}{ teleph_pc origin } & -0.00567 & & 0.0247 & & $-0.0761 * * *$ & & $0.0316^{*}$ & \\
\hline & 0.0242 & & 0.0324 & & 0.0226 & & 0.0182 & \\
\hline \multirow[t]{2}{*}{ distcap } & $-0.000848 * * *$ & $-0.00103 * * *$ & & & $-0.000799 * * *$ & $-0.00103 * * *$ & & \\
\hline & 0.000121 & 0.000104 & & & 0.000141 & $9.94 E-05$ & & \\
\hline \multirow[t]{2}{*}{ contig } & $4.848 * * *$ & $4.152 * * *$ & & & $3.678 * * *$ & $3.632 * * *$ & & \\
\hline & 0.557 & 0.415 & & & 0.471 & 0.356 & & \\
\hline \multirow[t]{2}{*}{ comcol } & $1.656^{* * *}$ & $2.304 * * *$ & & & $1.817 * * *$ & $3.552 * * *$ & & \\
\hline & 0.624 & 0.560 & & & 0.424 & 0.305 & & \\
\hline \multirow[t]{2}{*}{ comlang_ethno } & $1.051 * * *$ & $0.884 * *$ & & & $0.839 * * *$ & $0.657 * * *$ & & \\
\hline & 0.388 & 0.342 & & & 0.325 & 0.253 & & \\
\hline \multirow[t]{2}{*}{ comlang_off } & $1.423 * * *$ & $1.506^{* * *}$ & & & $2.077 * * *$ & $2.549 * * *$ & & \\
\hline & 0.463 & 0.428 & & & 0.406 & 0.39 & & \\
\hline \multirow[t]{2}{*}{ Constant } & $-28.46^{* * *}$ & $-34.71 * * *$ & 13.74 & 7.553 & $-21.49 * * *$ & $-34.50 * * *$ & 6.618 & 4.314 \\
\hline & 4.544 & 3.239 & 9.376 & 7.329 & 5.611 & 3.098 & 5.001 & 3.685 \\
\hline Overdispersion & & & & & $1.231 * * *$ & $1.015 * * *$ & & \\
\hline parameter (ln alpha) & & & & & 0.044 & 0.0347 & & \\
\hline Log likelihood & & & & & -5981.83 & -8796.30 & -2155.42 & -4614.58 \\
\hline AIC & & & & & 12001.67 & 17744.60 & 4336.83 & 9369.2 \\
\hline Wald $\chi^{2}$ & & & & & 683.33 & 2534.65 & 149.53 & 556.71 \\
\hline Prob $>\chi^{2}$ & & & & & 0.000 & 0.000 & 0.000 & 0.000 \\
\hline $\mathrm{R}^{2}$ & 0.433 & 0.533 & 0.089 & 0.221 & & & & \\
\hline Origin-time FE & NO & YES & NO & YES & NO & YES & $\mathrm{NO}$ & YES \\
\hline Origin-dest FE & $\mathrm{NO}$ & NO & YES & YES & $\mathrm{NO}$ & NO & YES & YES \\
\hline Observations & 738 & 1,152 & 738 & 1,152 & 738 & 1,152 & 496 & 1,034 \\
\hline
\end{tabular}

Note: $* * * \mathrm{p}<0.01, * * \mathrm{p}<0.05, * \mathrm{p}<0.1$. Robust standard errors (linear model) and bootstrap standard errors (negative binomial model) are reported in cursive.

The economic interpretation of these results is that migration is directed towards countries where urbanisation is taking place. Urbanisation in this context can be interpreted as growing opportunities. On the contrary, as a result of convergence between EU countries, 
poorer , and consequently less attractive, countries according to models 1 and 2, grew more. Thus, in these countries changes in GDP per capita would not be a strong signal for potential immigrants compared to the levels of GDP per capita. Most control variables stop being significant once this wide structure of fixed effects is considered. Again this is interpreted as a strong, robust indication of the effects of urbanisation on international migration in this set of countries over the considered period.

Table 5. Estimates results. Alternative measurements of urbanisation

\begin{tabular}{|c|c|c|c|c|c|c|}
\hline & \multicolumn{2}{|c|}{ Urb 1 Million } & \multicolumn{2}{|c|}{ Urb Small \& Med } & \multicolumn{2}{|c|}{ All Urban mesures } \\
\hline & Lineal & Neg Bin & Lineal & Neg Bin & Lineal & Neg Bin \\
\hline \multirow[t]{2}{*}{ Ln GDP pc dest } & $-1.119 * * *$ & 0.0625 & $-0.738 * *$ & -0.0171 & $-0.925 * * *$ & -0.076 \\
\hline & 0.35 & 0.290 & 0.339 & 0.409 & 0.346 & 0.191 \\
\hline \multirow[t]{2}{*}{ Urb large cities dest } & $0.231 * * *$ & -0.0147 & & & $0.253 * * *$ & 0.023 \\
\hline & 0.0446 & 0.170 & & & 0.045 & 0.017 \\
\hline \multirow{2}{*}{$\begin{array}{l}\text { Urb small \& medium } \\
\text { cities dest }\end{array}$} & & & 0.0211 & $0.0170 * * *$ & $0.0586^{*}$ & $0.0269 * * *$ \\
\hline & & & 0.0346 & 0.00484 & 0.0349 & 0.0083 \\
\hline \multirow[t]{2}{*}{ pop_0_14 dest } & $-0.175^{* * *}$ & -0.0192 & -0.0465 & -0.0126 & $-0.177 * * *$ & -0.0304 \\
\hline & 0.0419 & 0.246 & 0.0345 & 0.0278 & 0.0424 & 0.0321 \\
\hline \multirow[t]{2}{*}{ pop_m65 dest } & -0.0202 & 0.135 & $0.166^{* *}$ & $0.118 * *$ & -0.0435 & 0.0652 \\
\hline & 0.0863 & 0.176 & 0.0732 & 0.0568 & 0.0829 & 0.0656 \\
\hline \multirow[t]{2}{*}{ life_exp dest } & $-0.315^{* * *}$ & -0.0334 & 0.00417 & -0.0393 & $-0.277 * *$ & $-0.0707 *$ \\
\hline & 0.113 & 0.0600 & 0.104 & 0.0559 & 0.119 & 0.03885 \\
\hline \multirow[t]{2}{*}{ teleph_pc dest } & $0.0322 *$ & 0.0232 & -0.00281 & 0.0194 & 0.0283 & $0.0219 * * *$ \\
\hline & 0.0165 & 0.119 & 0.0167 & 0.0157 & 0.0173 & 0.0071 \\
\hline \multirow[t]{2}{*}{ Constant } & $39.20 * * *$ & 0.662 & 10.36 & 0.796 & $31.52 * * *$ & 3.600 \\
\hline & 8.974 & 6.366 & 9.803 & 6.021 & 10.7 & 3.397 \\
\hline Log likelihood & -1659.8 & -4626.1 & -1682.5 & -4617.1 & -1656.1 & -4614.4 \\
\hline AIC & 3427.6 & 9392.2 & 3473.0 & 9374.2 & 3422.2 & 9372.9 \\
\hline Wald $\chi^{2}$ & & 272.2 & & 441.2 & & 693.1 \\
\hline Prob $>\chi^{2}$ & & 0.000 & & 0.000 & & 0.000 \\
\hline $\mathrm{R}^{2}$ & 0.334 & & 0.307 & & 0.305 & \\
\hline Origin-time FE & YES & YES & YES & YES & YES & YES \\
\hline Origin-dest FE & YES & YES & YES & YES & YES & YES \\
\hline Observations & 1152 & 1034 & 1152 & 1034 & 1152 & 1034 \\
\hline
\end{tabular}

Note: $* * * \mathrm{p}<0.01, * * \mathrm{p}<0.05, * \mathrm{p}<0.1$. Robust standard errors (linear model) and bootstrap standard errors (negative binomial model) are reported in cursive.

Table 5 displays the disaggregated urbanisation rates. For brevity, I focused on the fixed effects of the linear and negative binomial models. As with the overall urbanisation measure, the linear estimates of both rate of urbanisation in large cities (>1 million inhabitants) and rate of urbanisation in small and medium-sized cities were positive, although the results were not always significant. Both urbanisation rates displayed significant and positive parameters in a linear model including both (col. 5). By contrast, the negative binomial model only reported significant results for urbanisation in the smaller 
cities. Thus, urbanisation is clearly a relevant process influencing intensity and direction of international migration flows. However, evidence is not robust on what specific 'type' of urbanisation (i.e. small-median or large cities) is acting as pull factor in our estimated models. The parameter for the log of GDP per capita is significantly negative in the linear estimates, and this again can be linked to convergence in the EU. Also, it could indicate that at some point there is a reverse effect of migration with origin in poorer countries on the average income per capita of the destination countries. This is because since the denominator of the monetary-related measure (population) is increased when there are more and more people with a smaller income per head.

I carried out a sensitivity analysis to check for the direct effects of economic development on immigration. The assumption has already been made that a solid link can be established between level of economic development and urbanisation. In order to isolate the effect of urbanisation on migration I drew a list of additional regressions to which I added non-linear relationships between economic development and urbanisation. Table 6 display the results for this analysis on log linear and negative binomial models where I account for the isolated measures of GDP per capita (model a) and urbanisation (model b). Also included are results for both measurements together (model c, which coincides with model 4 in table 4 and is repeated here for the reader's convenience), for the interaction between urbanisation and GDP per capita (model d), for the square of the log of GDP per capita (model e) and for both types of non-linearities (model f). Urbanisation in all models has positive effects (Table 6). The significance of the parameter is only dependent on whether the parameter is included in interaction with GDP pc in the negative binomial estimates. Thus, once we have controlled for the effects of all alternative sources of development on international immigration, we find urbanisation is permanently positive and significant. The interaction between GDP per capita and the urbanisation rate is negative but not significant. 
Table 6

\begin{tabular}{|c|c|c|c|c|c|c|c|c|c|c|c|c|}
\hline & \multicolumn{2}{|c|}{ Model a } & \multicolumn{2}{|c|}{ Model b } & \multicolumn{2}{|c|}{ Model c } & \multicolumn{2}{|c|}{ Model d } & \multicolumn{2}{|c|}{ Model e } & \multicolumn{2}{|c|}{ Model f } \\
\hline & Linear & Neg Bin & Linear & Neg Bin & Linear & Neg Bin & Linear & Neg Bin & Linear & Neg Bin & Linear & Neg Bin \\
\hline \multirow[t]{2}{*}{$\ln$ GDP pc dest } & $-0.818 * *$ & 0.0459 & & & -0.564 & -0.0837 & 0.332 & 0.730 & 2.139 & -1.333 & 1.952 & -1.365 \\
\hline & 0.355 & 0.180 & & & 0.358 & 0.176 & 0.982 & 0.550 & 2.173 & 3.171 & 2.189 & 1.624 \\
\hline \multirow[t]{2}{*}{ Urbanisation rate dest } & & & $0.106^{* * *}$ & $0.027 * * *$ & $0.101 * * *$ & $0.0279 * * *$ & $0.207^{* *}$ & 0.138 & $0.101 * * *$ & $0.0263 * * *$ & $0.191 *$ & 0.162 \\
\hline & & & 0.032 & 0.007 & 0.032 & 0.007 & 0.0937 & 0.135 & 0.032 & 0.010 & 0.101 & 0.240 \\
\hline \multirow[t]{2}{*}{$\ln$ GDP $\mathrm{pc}^{2}$ dest } & & & & & & & & & 0.180 & 0.074 & 0.117 & 0.138 \\
\hline & & & & & & & & & 0.147 & 0.191 & 0.167 & 0.147 \\
\hline $\ln$ GDP pc dest $*$ Urb & & & & & & & -0.013 & -0.0125 & & & -0.011 & -0.0155 \\
\hline rate dest & & & & & & & 0.011 & 0.011 & & & 0.012 & 0.026 \\
\hline \multirow[t]{2}{*}{ pop_0_14_dest } & -0.0502 & -0.0406 & $-0.094 * *$ & -0.038 & $-0.0874 * *$ & -0.0357 & $-0.0882 * *$ & -0.0312 & $-0.0808 * *$ & -0.0214 & $-0.0838 * *$ & -0.0291 \\
\hline & 0.034 & 0.028 & 0.037 & .0292 & 0.035 & 0.028 & 0.036 & 0.142 & 0.036 & 0.047 & 0.037 & 0.142 \\
\hline \multirow[t]{2}{*}{ pop_m65 dest } & $0.168^{* *}$ & $0.0957 * *$ & 0.0739 & 0.0460 & 0.077 & 0.053 & 0.0605 & 0.0595 & 0.0657 & $0.0672 *$ & 0.0558 & 0.0656 \\
\hline & 0.074 & 0.050 & 0.072 & 0.059 & 0.071 & 0.056 & 0.074 & 0.224 & 0.070 & 0.086 & 0.072 & 0.240 \\
\hline \multirow[t]{2}{*}{ life_exp dest } & -0.0198 & -0.0593 & -0.0556 & $-0.084 * *$ & -0.035 & $-0.0781 * *$ & -0.0513 & -0.0841 & $9.86 \mathrm{E}-05$ & -0.101 & -0.0263 & -0.0896 \\
\hline & 0.086 & 0.038 & 0.080 & 0.037 & 0.083 & 0.039 & 0.086 & 0.063 & 0.092 & 0.085 & 0.101 & 0.103 \\
\hline \multirow[t]{2}{*}{ teleph_pc dest } & -0.000281 & $0.0279 * * *$ & 0.0076 & $0.021 * * *$ & 0.002 & $0.023^{* * *}$ & 0.0128 & $0.0300^{* *}$ & 0.00937 & 0.0199 & 0.0161 & 0.0244 \\
\hline & 0.015 & 0.009 & 0.0136 & 0.007 & 0.014 & 0.008 & 0.017 & 0.012 & 0.014 & 0.020 & 0.016 & 0.046 \\
\hline \multirow[t]{2}{*}{ Constant } & $14.01 * *$ & 3.252 & 3.541 & 4.199 & 7.553 & 4.314 & 1.456 & -2.529 & -4.725 & 5.295 & -5.595 & 5.621 \\
\hline & 7.034 & 2.284 & 7.028 & 3.183 & 7.329 & 3.685 & 9.242 & 7.254 & 12.990 & 10.280 & 13.110 & 9.401 \\
\hline Log likelihood & -1682.99 & -4628.84 & -1671.9 & -4614.8 & -1670.54 & -4614.58 & -1669.06 & -4609.97 & -1669.70 & -4688.51 & -1668.73 & -4607.89 \\
\hline AIC & 3472.0 & 9395.7 & 3481.8 & 9367.6 & 3449.1 & 9369.2 & 3448.1 & 9361.9 & 3449.4 & 9519.0 & 3449.5 & 9359.8 \\
\hline Wald chi2 & & 658.75 & & 574.45 & & 556.71 & & 366.75 & & 111.66 & & 304.27 \\
\hline Prob > chi 2 & & 0.000 & & 0.000 & & 0.000 & & 0.000 & & 0.000 & & 0.000 \\
\hline $\mathrm{R}^{2}$ & 0.307 & & 0.320 & & 0.322 & & 0.323 & & 0.323 & & 0.324 & \\
\hline Origin-time FE & YES & YES & YES & YES & YES & YES & YES & YES & YES & YES & YES & YES \\
\hline Origin-dest FE & YES & YES & YES & YES & YES & YES & YES & YES & YES & YES & YES & YES \\
\hline Observations & 1152 & 1034 & 1152 & 1034 & 1152 & 1034 & 1152 & 1034 & 1152 & 1034 & 1152 & 1034 \\
\hline
\end{tabular}

Note: $* * * \mathrm{p}<0.01, * * \mathrm{p}<0.05, * \mathrm{p}<0.1$. Robust standard errors (linear model) and bootstrap standard errors (negative binomial model) are reported in cursive. 


\section{CONCLUSIONS}

This work has analysed the role of urbanisation in international immigration flows between the EU and the ENP. People from ENP countries migrate towards richer countries but not necessarily to more urbanised ones. Nevertheless, the fixed effects panel specifications, both for the linear and count data models, reported strongly robust results for effects of urbanisation on migration. Indeed, the growth of urbanisation matters more as a pull factor than the increases in GDP per capita. The convergence process occurring within the EU during the period analysed probably goes some way in explaining this.

Urbanisation is a strong pull factor and this may be linked with the growth of work opportunities in cities. On the other hand, immigrants not only look for monetary outcomes or for jobs, but also for non-economic territorial features. According to a disaggregated analysis, these opportunities have a greater weight for migrant decisions in small and medium-sized cities than in large cities.

The European Union is a world region with one of the lowest population growth rates and an ageing population. It is quite reasonable to assume that these growth rates may have been even negative without the international immigration flows. Moreover, these flows have often occurred towards countries with large and growing third-age cohorts. The urbanisation process ongoing in the EU during the considered period of analysis would have probably not have operated at the same intensity without these flows. Migration flows originated in population fast-growing and economically-depressed regions, for example from ENP-South countries, and thus can be thought to represent a 'win-win game' for both areas. On the contrary, ENP-East countries have been losing population from a fast emigration rate. The needs and specificities of each region (EU and ENP) call for an intensification of the European Neighbouring Policy. 


\section{REFERENCES}

- Angotti, T. (1996). "Latin American Urbanization and Planning: Inequality and Unsustainability in North and South," Latin American Perspectives 23(4), 12-34.

- Arellano, M. and Hahn, J. (2006). "Understanding Bias in Nonlinear Panel Models: Some Recent Developments", Invited Lecture, Econometric Society World Congress, London.

- Arzaghi, M. and Rupashinga, A. (2013) "Migration as a way to diversify: evidence from rural to urban migration in the U.S.", Journal of Regional Science, forthcoming.

- Baltagi, B.H. and Griffin, J.M. (1984), "Short and Long Run Effects in Pooled Models", International Economic Review, 25(3), 631-645.

- Barca, F., McCann, P., and Rodríguez-Pose, A. (2012). The case for regional development intervention: Place-based versus place-neutral approaches. Journal of Regional Science 52(1), 134-152.

- Beine, M., F. Docquier, and C. Özden (2011) "Diasporas," Journal of Development Economics, 95(1), 30-41.

- Beine, M., Bertoli, S., Fernández-Huertas Moraga, J. (2014) “A practitioners' guide to gravity models of international migration", Documento de Trabajo FEDEA 2014-03.

- Belot, M. and Ederveen, S. (2012) "Cultural barriers in migration between OECD countries", Journal of Population Economics, 25, pp 1077-1105.

- Bertoli, S. and Fernández-Huertas Moraga, J. (2011) "Multilateral Resistance to Migration", FEDEA working paper dt2011-04.

- Bloom, D. E., Canning, D., and Fink, G. (2008). "Urbanization and the wealth of nations," Science, 319(5864), 772-5.

- Borjas, G.J. (1987) "Self-selection and the earnings of immigrants", American Economic Review, 77 (1987), 531-553

- Brülhart, M., and Sbergami, F. (2009). "Agglomeration and growth: Cross-country evidence," Journal of Urban Economics, 65(1), 48-63.

- Burghhardt, A.F. (1971), A Hypothesis about Gateway Cities. Annals of the Association of American Geographers 61, 269-285.

- Burger, M. van Oort, F. and Linders, G.J. (2009) "On the Specification of the Gravity Model of Trade: Zeros, Excess Zeros and Zero-inflated Estimation”, Spatial Economic Analysis, 4(2), 167-190.

- Cameron, C. \& Trivedi, P.K. (2005) Microeconometrics: Methods and Applications, Cambridge University Press, New York.

- Caragliu, A., Del Bo, C., de Groot, H.L.F. and Linders G.M. (2012) "Cultural determinants of migration", Annals of Regional Science, in press.

- Cheng, I-H. and Wall, D. (2005) "Controlling for heterogeneity in gravity models of trade an integration", Federal Reserve Bank of St. Louis Review, (81(1), 49-63.

- Cheshire, P. and Magrini, S. (2006) "Population Growth in European Cities: Weather Matters - But Only Nationally," Regional Studies, 40(1), 23-37.

- Clark, X., Hatton, T.H. and Williamson, F.G. (2007) "Explaining US immigration, 1971-1998", The Review of Economics and Statistics, 89(2), 359-373.

- Combes, Pierre-Philippe, Gilles Duranton, and Laurent Gobillon (2011) "The identification of agglomeration economies", Journal of Economic Geography, 11(2), 253-266.

- Diez T. (2005), Constructing the Self and Changing Others: Reconsidering 'Normative Power Europe', Millennium: Journal of International Studies 33(3), 613-36. 
- Dupont, V. (2007). "Do geographical agglomeration, growth and equity conflict?" Papers in Regional Science, 86, 193-213.

- Duranton, Gilles and Diego Puga (2004) "Micro-foundations of urban agglomeration economies", in Vernon Henderson and Jacques-François Thisse (eds.) Handbook of Regional and Urban Economics, volume 4 . Amsterdam: North-Holland, 2063-2117.

- Faggian, A. and Royuela, V. (2010), "Migration Flows and Quality of Life in a Metropolitan Area: the Case of Barcelona-Spain”, Applied Research in Quality of Life, 5(3), pp 241-259.

- Florida, R. (2002) The Rise of the Creative Class: And How It's Transforming Work, Leisure, Community and Everyday Life. New York: Basic Books.

- Frey, W. H. (1996) "Immigration, Domestic Migration, and Demographic Balkanization in America: New Evidence for the 1990s." Population and Development Review 22(4):741-763.

- Frey, W. H. (2002) "U.S. Census Shows Different Paths for Domestic and Foreign-Born Migrants," Population Today 30, no. 6: 3-5.

- Gawrich A., Melnykovska I. and Schweickert R. (2010), Neighbourhood Europeanization through ENP: The Case of Ukraine, Journal of Common Market Studies, 48(5), 1209-1235.

- Gheasi, M., Nijkamp, P., Poot, J. (2012) "Special issue on international migration: editorial introduction", Annals pf Regional Science, in press.

- Glaeser, Edward L. and David C. Maré. (2001) "Cities and skills" Journal of Labor Economics, 19(2), 316-342.

- Grogger, J., and G. H. Hanson (2011) "Income maximization and the selection and sorting of international migrants," Journal of Development Economics, 95(1), 42-57.

- Guimarães, P., Figueiredo, O. \& Woodward, D. (2003) A tractable approach to the firm location decision problem. Review of Economics and Statistics, 85, 201-204.

- Harris, J. R., and Todaro, M. P. (1970). Migration, unemployment and development: a two-sector analysis. American Economic Review 60: 126-142.

- Henderson, V. (2003). "The Urbanization Process and Economic Growth: The So-What Question," Journal of Economic Growth 8, 47-71.

- Hyde-Price A. (2006), 'Normative' power Europe: a realist critique, Journal of European Public Policy, 13: 2, 217-234.

- Johnston, R.J. (1982) The American Urban System: A Geographical Perspective. London: Longman.

- Kim, K. and Cohen, J.E. (2010) "Determinants of International Migration Flows to and from Industrialized Countries: A Panel Data Approach Beyond Gravity", International Migration Review, 44(4), 899-932.

- Kundu, A. (2009). "Urbanisation and migration: an analysis of trend, pattern and policies in Asia", Human Development Research Paper 2009/16, retrieved online on Jan 152014 at the URL http://hdr.undp.org/en/reports/global/hdr2009/papers/HDRP_2009_16.pdf

- Lewis, W. A. (1954) "Economic Development with Unlimited Supplies of Labour" Manchester School of Economic and Social Studies, 22, 139-191.

- Martin, P. (2003) "Economic Integration and Migration: The Mexico-US Case." UNU/WIDER. Discussion Paper No. 2003 / 35. Helsinki, Finland: United Nations University/World Institute for Development and Economic Research

- Marshall, Alfred (1890) Principles of Economics. London: Macmillan 
- Massey, D.S. Arango, J Hugo, G Kouaouci, A., Pellegrinoand, A. and Taylor, J.E., (1993) "Theories of International Migration: A Review and Appraisal", Population and Development Review, 19(3), 431-466.

- Mayda, A. M. (2010) "International migration: a panel data analysis of the determinants of bilateral flows," Journal of Population Economics, 23(4), 1249-1274.

- Milanovic (2011) "A short history of global inequality: The past two centuries", Explorations in Economic History, 48(4), 494-506.

- Monastiriotis, V. Borrell, M. (2012) Political and Political Economy Literature on the ENP: Issues and Implications WP1/05 SEARCH working paper

- Neumayer, E. (2005) “Bogus Refugees? The Determinants of Asylum Migration to Western Europe.” International Studies Quarterly 49:389-409.

- OECD (2009a) How Regions Grow, Paris. Organisation for Economic Cooperation and Development.

- OECD (2009b). Regions Matter: Economic Recovery, Innovation and Sustainable Development. Paris. Organisation for Economic Cooperation and Development.

- OECD (2009c). Regions at a Glance. Paris. Organisation for Economic Cooperation and Development.

- Ortega, F., and G. Peri (2009) "The Causes and Effects of International Migrations: Evidence from OECD Countries 1980-2005," NBER Working Paper No. 14883, National Bureau of Economic Research.

- Özden, C.., Parsons, C.R. Schiff, M. and Walmsley, T.L. (2011) "Where on earth is everybody? The evolution of global bilateral migration 1960-2000", The World bank Economic Review, 25(1), 12-56.

- Partridge, M. and Rickman, D. (2003) "The Waxing and Waning of US Regional Economies: The Chicken-Egg of Jobs Versus People," Journal of Urban Economics, 53, 76-97.

- Partridge, M. and Rickman, D. (2006) "Fluctuations in Aggregate US Migration Flows and Regional Labor Market Flexibility," Southern Economic Journal, 72, 958-980.

- Pedersen, P. J., M. Pytlikova, and N. Smith (2008) "Selection and network effectsMigration flows into OECD countries 1990-2000," European Economic Review, 52(7), 1160-1186.

- Pirotte, A. (1999), "Convergence of the static estimation toward the long run effects of dynamic panel data models", Economic Letters, 63, 151-158.

- Puga, D. (2010) "The magnitude and causes of agglomeration economies" Journal of Regional Science, 50, 203-219.

- Ranis, G. and Fei, J.C.H. (1961), “A Theory of Economic Development," American Economic Review, 51, 533-565.

- Ramos, R. (2013) "Analysing migration flows from and to ENC through the MIGSEARCH databases" WP3/01 SEARCH Working Paper.

- Rodríguez-Pose, A. and Ketterer, T.D. (2012) "Do local amenities affect the appeal of regions in Europe for migrants?" Journal of Regional Science, 52(4), 535-561.

- Rosenthal,S. and Strange, W. (2004). "Evidence on the Nature and Sources of Agglomeration Economies," Handbook of Urban and Regional Economics, Vol. 14, Geography and Cities J.V. Henderson and J-F Thisse eds.

- Roy, A.D., (1951) "Some thoughts on the distribution of earnings" Oxford Economic Papers, 3, 135-146.

- Ruiz, J.M and Villarubia, J.M. (2007) "The wise use of dummies in gravity models: export potentials in the Euromed region", Banco de España Working Papers Series, n. 0720 . 
- Santos Silva, J.M.C., Tenreyro, S. (2006) "The log of gravity" Review of Economics and Statistics, 88(4), 641-658.

- Sempere, M.M. and Calatayud, C.R. (2012) 'Reemigrar en España: una aproximación a sus determinantes', Investigaciones Regionales, 22, pp.105-128.

- Sen, A. (1987), The Standard of Living (University Press, Cambridge).

- Todaro, M.P. (1976) Internal Migration in Developing Countries. Geneve. International Labour Organization.

- Wesselink , E. and Boschma, R. (2012) "Overview of the European Neighbourhood Policy: Its History, Structure, and Implemented Policy Measures”, WP1/04 SEARCH working paper.

- Williamson, J. G. (1988). "Migration and urbanization", in D. Rodrik and M. Rosenzweig (eds), Handbook of Development Economics, Vol. 1, Ch. 11: 425-465.

- World Bank (2009). World Development Report 2009: Reshaping economic geography. Washington D.C: World Bank. 


\section{Appendix 1}

Poisson Estimates

\begin{tabular}{|c|c|c|c|c|c|c|c|}
\hline & Model 1 & Model 2 & Model 3 & Model 4a & Model 4b & Model 4c & Model 4d \\
\hline \multirow[t]{2}{*}{$\ln$ GDP pc dest } & 0.542 & 0.314 & 1.089 & -0.229 & -0.161 & -0.167 & -0.105 \\
\hline & 0.358 & 0.338 & 0.916 & 0.749 & 0.748 & 0.746 & 0.770 \\
\hline \multirow[t]{2}{*}{ Urbanisation rate dest } & $-0.0437 * * *$ & $-0.0502 * * *$ & 0.00896 & 0.0101 & & & \\
\hline & 0.0129 & 0.0125 & 0.0336 & 0.0357 & & & \\
\hline \multirow[t]{2}{*}{ Urb 1 Million } & & & & & -0.0278 & & -0.0209 \\
\hline & & & & & 0.0944 & & 0.0884 \\
\hline \multirow[t]{2}{*}{ Urb Small \& Medium } & & & & & & 0.0140 & 0.0122 \\
\hline & & & & & & 0.0401 & 0.0382 \\
\hline \multirow[t]{2}{*}{ pop_0_14 dest } & -0.135 & -0.0634 & -0.106 & -0.119 & -0.110 & -0.117 & -0.112 \\
\hline & 0.122 & 0.118 & 0.0656 & 0.0729 & 0.0717 & 0.0719 & 0.0727 \\
\hline \multirow[t]{2}{*}{ pop_m65 dest } & $0.329 * * *$ & $0.676 * * *$ & $0.286^{*}$ & $0.390 * * *$ & $0.405 * * *$ & $0.389 * * *$ & $0.395 * * *$ \\
\hline & 0.125 & 0.140 & 0.164 & 0.132 & 0.129 & 0.128 & 0.134 \\
\hline \multirow[t]{2}{*}{ life_exp dest } & $0.532 * * *$ & $0.398 * * *$ & 0.0366 & 0.0958 & 0.0990 & 0.107 & 0.115 \\
\hline & 0.102 & 0.0862 & 0.126 & 0.109 & 0.122 & 0.124 & 0.140 \\
\hline \multirow[t]{2}{*}{ teleph_pc dest } & $-0.0625 * * *$ & $-0.0903^{* * *}$ & -0.0294 & -0.00323 & -0.00454 & -0.00389 & -0.00479 \\
\hline & 0.0237 & 0.0237 & 0.0236 & 0.0309 & 0.0328 & 0.0316 & 0.0335 \\
\hline \multirow[t]{2}{*}{$\ln$ GDP pc origin } & $0.940 * *$ & & -0.682 & & & & \\
\hline & 0.468 & & 0.668 & & & & \\
\hline \multirow[t]{2}{*}{ Urbanisation rate origin } & $0.0775 * * *$ & & -0.0216 & & & & \\
\hline & 0.0230 & & 0.0408 & & & & \\
\hline \multirow[t]{2}{*}{ pop_0_14 origin } & -0.0579 & & -0.0592 & & & & \\
\hline & 0.0774 & & 0.0491 & & & & \\
\hline \multirow[t]{2}{*}{ pop_m65 origin } & $0.293 * *$ & & 0.0605 & & & & \\
\hline & 0.136 & & 0.181 & & & & \\
\hline \multirow[t]{2}{*}{ life_exp origin } & $-0.234 * * *$ & & -0.0365 & & & & \\
\hline & 0.0678 & & 0.0665 & & & & \\
\hline \multirow{2}{*}{ teleph_pc origin } & $-0.278 * * *$ & & 0.00291 & & & & \\
\hline & 0.0614 & & 0.0334 & & & & \\
\hline \multirow[t]{2}{*}{ distcap } & $-0.000892 * * *$ & $-0.000959 * * *$ & & & & & \\
\hline & 0.000206 & 0.000205 & & & & & \\
\hline \multirow[t]{2}{*}{ contig } & $2.471 * * *$ & $1.976^{* * *}$ & & & & & \\
\hline & 0.878 & 0.506 & & & & & \\
\hline \multirow[t]{2}{*}{ comcol } & $1.337 *$ & $2.803 * * *$ & & & & & \\
\hline & 0.727 & 0.474 & & & & & \\
\hline \multirow[t]{2}{*}{ comlang_ethno } & $1.263 * * *$ & $1.115^{* *}$ & & & & & \\
\hline & 0.472 & 0.557 & & & & & \\
\hline \multirow[t]{2}{*}{ comlang_off } & $2.113 * * *$ & $2.523 * * *$ & & & & & \\
\hline & 0.431 & 0.501 & & & & & \\
\hline \multirow[t]{2}{*}{ Constant } & $-24.33 * *$ & $-23.72 * * *$ & & & & & \\
\hline & 11.45 & 7,015 & & & & & \\
\hline Log likelihood & -11334774 & -12363850 & -309380.3 & -519696.0 & -519640.5 & -519286.4 & -519024.9 \\
\hline AIC & 22669585 & 24727850 & 618784.6 & 1039530 & 1039419 & 1038681 & 1038160 \\
\hline Origin-time FE & NO & YES & NO & YES & YES & YES & YES \\
\hline Origin-dest FE & NO & NO & YES & YES & YES & YES & YES \\
\hline Observations & 738 & 1152 & 496 & 1034 & 1034 & 1034 & 1034 \\
\hline
\end{tabular}

